Relations industrielles

Industrial Relations

\title{
Application de la convention collective et administration du personnel
}

Jean Gagné

Volume 4, numéro 8, avril 1949

URI : https://id.erudit.org/iderudit/1023512ar

DOI : https://doi.org/10.7202/1023512ar

Aller au sommaire du numéro

\section{Éditeur(s)}

Département des relations industrielles de l’Université Laval

\section{ISSN}

0034-379X (imprimé)

1703-8138 (numérique)

Découvrir la revue

\section{Citer cet article}

Gagné, J. (1949). Application de la convention collective et administration du personnel. Relations industrielles / Industrial Relations, 4(8), 73-74.

https://doi.org/10.7202/1023512ar
Résumé de l'article

L'attitude des employeurs devant les unions ouvrières comme unités de négociation de la convention collective de travail

nériacion de la convention collective de travail 


\title{
APPLICATION DE LA CONVENTION COLLECTIVE ET ADMINISTRATION DU PERSONNEL
}

\author{
L'attitude des employeurs devant les unions ouvrières comme unités \\ de négociation de la convention collective de travail
}

JeAN GaGnÉ

Si nous parlons de l'administration de la convention collective extensionnée (du décret), nous savons que la responsabilité première de la bonne application du décret relève du comité paritaire. Le directeur du personnel ne peut alors servir qu'à interpréter, soit au profit du patron, soit au profit des employés, les conflits qui peuvent survenir à l'intérieur de l'entreprise, conflits causés par une mauvaise application du décret. Dans ce cas, son rôle se borne, la plupart du temps, à faire des suggestions à l'employé et à l'employeur. Nous n'avons pas l'intention de traiter longuement de cet aspect du problème de l'administration du décret parce qu'il relève d'un organisme extérieur à l'entreprise.

Si dans une entreprise commerciale ou industrielle les relations du travail ne sont conditionnées que par une convention collective particulière, l'administration de la convention crée alors de nouveaux liens et de nouvelles responsabilités dans les relations entre employeurs et employés. Ainsi l'administration de la convention pose un problème de relations entre les représentants de l'administration de l'entreprise et ceux des associations ouvrières. Le comité de griefs ou de relations ouvrières, généralement formé en vertu de l'une des clauses de la convention devient l'instrument principal qu'ont entre les mains les représentants de l'union pour surveiller la bonne administration de la convention. Le comité de griefs est certes le meilleur moyen direct qui existe pour diminuer la distance qui sépare les employeurs et les employés d'une même entreprise et pour préparer, à longue portée, les futures négociations qui pourront se faire dans un esprit plus amical et plus compréhensif des besoins des travailleurs comme de ceux du patron. De cette façon, l'on pourra peut-être obtenir de meilleures clauses dans les futures conventions collectives. Mais nous ne traiterons pas ici de l'importance ou du fonctionnement de ces comités de griefs ainsi que de la procédure de règlement de griefs.

Nous nous bornerons à l'étude du problème que pose à la direction du personnel dans une entreprise le fait de la convention collective. Nous croyons que des relations du travail régies par les clauses d'une convention collective peut aider non seulement le travailleur à revendiquer ses droits et privilèges dans l'entreprise, mais aussi aider la direction dans l'administration de son personnel et même être profitable à l'entreprise à tout point de vue. Nous croyons que tout le problème ( si problème il y a) réside dans une question d'attitude d'esprit des deux parties à la convention. Et c'est sous cet angle que nous traiterons le sujet.

Le fait de la convention collective a pris sa place dans les moeurs industrielles de nos jours, qu'on le veuille ou non. Il s'agit de savoir comment il peut s'intégrer dans le travail des directeurs d'une entreprise et du directeur du personnel, car de plus en plus il influence la manière d'administrer l'entreprise et de diriger le personnel, et de plus en plus joue le rôle d'entremetteur entre patrons et ouvriers. Il s'agit donc de comprendre que la convention collective, en plus d'être un merveilleux instrument de négociation de conditions de travail meilleures pour les employés, a une valeur qui peut se traduire en terme profits et progrès industriels pour les patrons.

La première attitude que nous étudierons est celle des patrons devant les unions comme unités de négociation de la convention collective. Les patrons peuvent se diviser en deux catégories: ceux qui sont opposés au syndicalisme et à tout ce qui en découle, en théorie ou en pratique ou les deux à la fois et ceux qui acceptent le fait de l'organisation (association) professionnelle avec ses conséquences.

Ceux de la première catégorie essaient par leur conduite de nuire le plus possible au développement des organisations de travailleurs. Leur esprit est préjugé surtout quand il s'agit de négocier avec les unions. Il s'agit alors pour eux de se servir de tous les moyens possibles pour faire obstruction aux demandes des employés dans la négociation de la convention. Ils ne voient pas quelles fonctions légitimes peuvent jouer les unions dans 
les décisions à prendre concernant la règlementation des conditions de travail, la fixation des salaires, la description et la répartition des tâches, etc. Ils supportent ces unions parce qu'ils y sont obligés et essaient de se soustraire à leur intervention par des moyens légaux.

Tandis que ceux de la deuxième catégorie, (dont plusieurs représentants de la grande industrie et du gros commerce) - catégorie composée surtout d'importantes compagnies v.g. les compagnies de chemin de fer, l'industrie de l'imprimerie, de la construction, etc. - négocient de bonne foi avec les membres de leur union depuis de nombreuses années. Après cette expérience, ils croient qu'il est possible de discuter avec une union de salaires et de conditions de travail sur une base d'entente collective qui est raisonnable et orientée vers des relations du travail mieux ordonnées, plus pacifiques, servant les intérêts des employés et des employeurs tout en favorisant le progrès de l'industrie.

Evidemment, il y a différentes catégories d'unions ou de syndicats ayant chacune ou chacun leurs méthodes, leurs tendances, leur manière de négocier une convention collective et de la faire administrer dans le sens de leurs buts et visées. L'expérience a démontré que le régime de la convention collective, à cause de ces divers genres d'organisations professionneiles, peut présenter des avantages et des désavantages. D’après certains, le témoignage est contradictoire.

Il s'agit donc de découvrir quelle doit être la véritable orientation des relations qui doivent exister entre les employeurs et les unions ouvrières dans l'administration de la convention collective. Bien qu'actuellement, on ne puisse pas encore dire que le régime de la convention collective extensionnée ainsi que celui de la convention collective particulière n'aient produit que des résultats avantageux pour l'industrie, le commerce et les servi. ces publics, il apparaît, de toute façon, que dains notre pays, le régime de l'entente collective ne pourra survivre et améliorer véritablement nos relations de travail que si certains résultats réels tant au point de vue production et rendement qu'au point de vue progrès social ne soient augmentés.

D'une part, les industriels ne négocient pas avec les unions pour vivre une théorie ou tout simplement pour favoriser l'accroissement ou la force des unions ouvrières. D'autre part, les unions ouvrières, par la place qu'elles ont prise dans le monde industriel et commercial, sont devenues pour les industriels même un facteur essentiel qui conditionne la vie et le progrès de toute industrie et de toute entreprise.

Mais cette place qu'elles ont prise dans la vic industrielle n'est justifiée que par ce désir qu'elles doivent continuellement avoir, dans la négociation et l'application de la convention collective, que les deux parties en arrivent à une meilleure compréhension, dans les relations patronales-ouvrières, de leurs droits et devoirs légitimes.

Les directeurs d'entreprises et les gérants du personnel dérogeraient donc à leurs devoirs professionnels d'experts en relations du travail s'ils envisageaient d'un autre oeil la négociation et l'application d'une convention. De par la responsabilité de leurs fonctions ils doivent travailler en harmonie avec les représentants du travail organisé et favoriser le développement, dans la droite ligne, de cette nouvelle méthode de traiter avec leurs employés, par l'intermédiaire d'unions, en se soumettant aux clauses d'une entente collective, d'un décret loi ou des deux à la fois. Sinon, ils nuisent au véritable progrès de l'industrie, distraient les groupements ouvriers de leurs fins professionnelles, et les obligent à se réfugier dans une attitude qui est loin du véritable esprit de collaboration qui est censé animer les deux parties à la convention.

Et ainsi nous voyons que l'attitude des employeurs devant les unions ouvrières comme unités de négociation de la convention collective de travail peut amener plus de paix ou plus de désordre dans le monde de l'industrie, du commerce et des services publics. 